\title{
Identification of Inpatient DNR Status: A Safety Hazard Begging for Standardization
}

\author{
Niraj L. Sehgal, MD, MPH \\ Robert M. Wachter, MD
}

Division of Hospital Medicine, University of California, San Francisco, San Francisco, California
We thank Mark Keroack, MD, MPH, and Cathy Krsek, RN, MSN, MBA, from the University HealthSystem Consortium for their contributions to the survey and assistance with administration. We also thank members of the UHC Chief Nursing Council for participating in the survey study.

Dr. Wachter is a member of the Scientific Advisory Boards of Google Health, Intellidot, Codigy, and Hoana Medical and a member of the Board of Directors of the American Board of Internal Medicine.
BACKGROUND: Ascertaining and documenting patients' preferences regarding endof-life care is required by accrediting organizations at hospital admission. However, hospitals vary widely in their methods of making these preferences (including do-not-resuscitate [DNR] status) available to frontline providers, increasing the potential for errors.

METHODS: We surveyed 127 nursing executive members of the University HealthSystem Consortium (an alliance of academic medical centers), asking them to describe the current practices of their hospitals in identifying DNR orders. For those at institutions using color-coded wristbands, we also asked about other patient data depicted by wristbands and the choice of colors for DNR and these other indications. We used a commercial online survey tool with E-mail distribution.

RESULTS: Sixty-nine nurse executives completed the survey (54\%). Fifty-six percent of hospitals use paper documentation as their only mode to identify DNR orders, $16 \%$ use electronic health records, and 25\% augment either paper or electronic documentation with a color-coded patient wristband. Of those using color-coded wristbands ( $\mathrm{n}=17$ ), 8 color schemes were reported. More than $70 \%$ of respondents recalled situations when confusion around a DNR order led to problems in patient care.

CONCLUSIONS: Mechanisms to identify DNR orders vary significantly. For hospitals that use color-coded wristbands, the variety of color choices poses a risk for confusion and error. Building on existing and isolated state initiatives, a national mandate to standardize DNR identification and the color of patient wristbands would reduce the potential for errors and promote adherence to patients' wishes. Journal of Hospital Medicine 2007;2:366-371. (C) 2007 Society of Hospital Medicine.

KEYWORDS: patient safety, standardization, Do Not Resuscitate orders, patient wristbands.

A s modern medicine developed the technological capacity to Adeliver aggressive life-sustaining interventions-through methods such as cardiopulmonary resuscitation (CPR), intensive care units, and mechanical ventilation-the concept of do-notresuscitate (DNR) orders emerged to allow individual patients to choose to forego selected treatments. To encourage patients to articulate these preferences, Congress passed the Patient SelfDetermination Act in 1991, a measure that required health care facilities to discuss advance directives with patients as they enter their system. ${ }^{1}$ Although the act has had less of an impact on the quality of DNR discussions than originally hoped for, ${ }^{2-5}$ its passage was evidence of the importance our society places on patient-clinician discussions regarding goals of care. In addition to this legislative push, many organizations and advocacy groups use 
a variety of marketing campaigns, accreditation standards, ${ }^{6}$ and standard instruments and tools ${ }^{7-9}$ to promote the use of advance directives

Despite all these efforts, fewer than $30 \%$ of Americans (54\% older than age 65) have completed advance directives. ${ }^{10}$ Nevertheless, many patients-particularly those at highest risk for requiring end-of-life care-do express preferences regarding resuscitation at the time of hospital admission. In an ideal world, these preferences would be available for all providers to view, respect, and act on.

Unfortunately, research on patient safety and quality has demonstrated wide gaps between ideal and actual practice. ${ }^{11-12}$ In the context of DNR wishes, despite strong efforts to collect patients' preferences, no current regulation provides or mandates a "best practice" on making these preferences operational. There are also few data that indicate whether patients' preferences are in fact transmitted to providers at the point of care and in an accurate and reliable manner.

Past research on proper identification of DNR orders is limited, with much of the focus on prehospital protocols. ${ }^{13-15}$ Anecdotally, hospitals seem to employ varying strategies to highlight DNR orders using a combination of paper or electronic documentation and color-coded patient wristbands. There have been several reports of errors involving this issue, including patients receiving CPR despite stated DNR preferences and a patient having CPR withheld because the wrong chart (of another patient with a DNR order) was mistakenly pulled. ${ }^{16-17}$

The patient safety field emphasizes standardization as a key strategy to prevent errors. Because of problems articulating DNR orders (and other important patient-related information), several hospitals promote the use of color-coded wristbands to denote preferences for resuscitation. However, without national regulations or standards, the possibility remains that one safety hazard (advance directives on a paper chart distant from a patient's room) may be traded for another hazard (front-line providers interpreting a colorcoded wristband incorrectly). In addition to the ethical problems inherent in failing to adhere to patients' resuscitation preferences, errors in following advance directives may also create legal liability. ${ }^{18}$ With all this in mind, we conducted a national survey to determine practice variations in the identification of DNR orders and the use of color-coded patient wristbands. We hypothesized that there is considerable variation both in identification practices and in the use of color-coded wristbands across academic medical centers.

\section{METHODS}

The project was approved by the University of California, San Francisco Committee on Human Research. We anonymously surveyed nursing executives who are members of the University HealthSystem Consortium (UHC), an alliance of 97 academic medical centers and their affiliated hospitals representing $90 \%$ of the nation's nonprofit academic medical centers. ${ }^{19}$ The nursing executives are senior nursing leaders at participating UHC institutions and members of a dedicated UHC Chief Nursing Officer Council E-mail listserv. We designed a brief survey and distributed it via their E-mail listserv using an online commercial survey administration tool. ${ }^{20}$ Respondents were asked to complete the survey or have one of their colleagues familiar with local DNR identification practices complete it on their behalf. The online tool also provided summary reports and descriptive findings to meet the study objectives. We provided a 1-month window (during summer 2006) with 1 interval E-mail reminder to complete the surveys.

\section{RESULTS}

Survey announcements were E-mailed to 127 nursing executives, 69 of whom completed it (re-

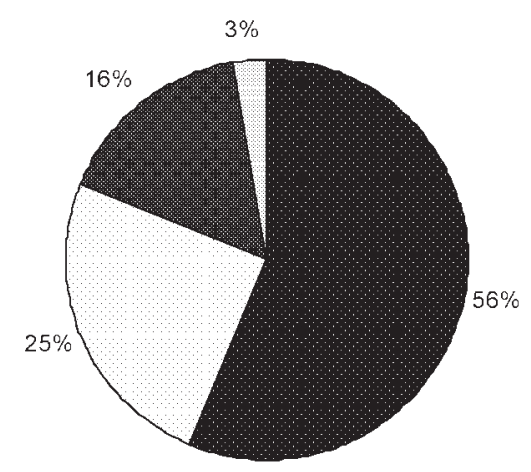

Paper Chart Documentation $(n=39)$
Use of Wris tband with either Paper or Electronic Documentation ( $n=17)$
Electronic Health Record $(n=11)$
Other $(n=2)$--converting from Paper to EHR

FIGURE 1. Current practices for identification of DNR orders. 
TABLE 1

Reported Colors Used for Wristbands Designating DNR Status and the Number Using Them

- Green-5

- Yellow-3

- Blue-3

- White with blue stars versus green stars (full DNR versus limited DNR)-1

- Red-1

- Red and white-1

- Purple-1

- Gold-1

- Other (not listed)-

sponse rate $54 \%$ ). The respondents represented mostly academic medical centers (87\%; another $13 \%$ represented affiliated community teaching hospitals), public institutions (89\%), and large facilities $(60 \%$ with more than 400 beds; $40 \%$ with 201-400 beds). More than half the respondents (56\%) reported their hospitals use paper chart documentation as the only method of identifying patients with a DNR order, whereas $16 \%$ reported their hospitals use only electronic health record (EHR) documentation (Fig. 1). Twenty-five percent of hospitals $(n=17)$ use a color-coded patient wristband in addition to either paper or electronic documentation. Of these 17 hospitals, a total of 8 colors or color schemes were employed to designate DNR status (Table 1).

The use of color-coded wristbands was not limited to identification of DNR status. Fifty-five percent of hospitals $(n=31)$ use color-coded wristbands to indicate another piece of patient-related data such as an allergy, fall risk, or "same last name” alert (Table 2). In fact, 12 indications were depicted by various colors, with variations in both the color choice for a given indication (eg, allergy wristbands red at one hospital and yellow at another) and across indications (eg, red for allergy at one hospital and red for bleeding risk at another). Nearly 3 of 4 respondents $(n=48)$ reported "being aware of a case at your institution in which confusion about a DNR order led to problems or confusion in patient care." A few respondents shared a brief anecdote of the event, illustrating the spectrum of clinical scenarios that lead to potential confusion (Table 3). Respondents reporting a case of confusion were not more likely to be from an institution that used color-coded wristbands.

When asked whether most ("greater than 75\%") physicians and nurses could properly identify the color associated with a DNR patient wrist-
TABLE 2

Other Reported Indications Colors Used for Patient Wristbands

\begin{tabular}{ll}
\hline Indication (n) & Colors used (n) \\
\hline Drug/allergy (22) & Red (16) \\
& Yellow (4) \\
& White (1) \\
& Orange (1) \\
Fall risk (18) & Orange (5) \\
& Green (3) (and lime green [1]) \\
& Blue (3) \\
& Purple (3) \\
Same name alert (7) & Yellow (2) (and fluorescent yellow [1]) \\
& Blue (3) \\
Bleeding risk (3) & Orange (2) \\
Patient identification (3) & Yellow'2) \\
Sleep apnea (1) & Red \\
\hline Wandering risk (3) & Green \\
Contact isolation (2) & Red \\
Latex allergy (2) & White \\
No blood draws on this arm (1) & Pink (2) (and hot pink [1]) \\
MRSA infection (1) & Green \\
No blood products (1) & Purple \\
Orange \\
Green \\
Red \\
Purple \\
\hline
\end{tabular}

TABLE 3

Anecdotes about Confusion around a DNR order

"The patient had a DNR order written in the chart but no other identifiers at bedside, so a consult service started CPR while trying to determine code status."

"Nurse called a code on a patient who was DNR because she failed to see order in chart."

"Resuscitation efforts took place on a patient with a DNR order because the entire chart did not accompany the patient to a diagnostic testing area."

"Patient was off the unit for a procedure, and staff in the other department did not know patient's code status (DNR) and called a code."

"Patient transported off nursing unit to radiology and 'coded.' Patient was a DNR, but the order was 'buried' in thinned chart materials."

"Prior to implementing the wristbands, there were delays in care. Once wristbands were implemented with stars only, there was confusion as to what a blue star meant and what a green star meant (limited versus no resuscitation efforts)."

"We used to place a sticker on the chart. A sticker was left on the chart of a discharged patient when a new patient was admitted. The mistake was caught before an incident occurred."

band, responses differed by discipline. Eight-five percent of respondents believed that most nurses at their institutions could correctly report the color for DNR, whereas only $15 \%$ believed physicians could do the same. Only $22 \%$ of respondents anticipated a change in the current system within the next 2 years; all these changes were a transition from paper to electronic documentation systems. 


\section{DISCUSSION}

Regardless of whether the DNR documentation occurs in paper or electronic form (and our study demonstrates significant practice variation in the documentation method), the risk that a hospitalized patient may suddenly stop breathing or become pulseless is ever present. When such a patient is discovered, providers race to the bedside and initiate care, but immediately ask, "Is the patient a full code?" In these often-chaotic moments, accurate and timely information about DNR status is critical to respecting a patient's preferences and avoiding a potentially devastating error. A number of the anecdotes shared by survey respondents and highlighted in Table 3 reinforce this concern. Many of these scenarios occur in the middle of the night or off a patient's primary unit (ie, at a test or procedure area), increasing the need for quick and easy identification of DNR status.

Our study demonstrates that a logical point-ofcare solution-a color-coded DNR patient wristband-may create its own safety hazards, particularly if the color designations are not known by all providers (including floating and traveling nurses or trainees who rotate at different hospitals) and if the colors being employed represent different indications at a given hospital (see accompanying Images Dx, page 445). We found that approximately 1 in 4 surveyed hospitals depict DNR status by a color-coded wristband. We also discovered remarkable variation in the colors chosen and the degree to which institutions use color-coded wristbands to signal a panoply of other patient-related issues. Human factors research demonstrates that even well-meaning patient safety solutions may cause harm in new ways if they are poorly implemented or if the interface between the technology and human work patterns is not well appreciated. For example, recent studies illustrate unintended consequences from safety-driven solutions, such as the implementation of computerized order entry, ${ }^{21-22}$ quality measurement, ${ }^{23}$ adoption of EHRs, ${ }^{24}$ and bar code medication administration systems. ${ }^{25} \mathrm{Be}$ cause standardization is a key mechanism for decreasing the opportunities for error, our findings raise serious concerns about current wristband use.

Interestingly, the lack of standardization and its related risk of failing to recall the conditions associated with color-coded wristbands are complicated by societal trends. In December 2004 the issue of patient wristbands made headlines in Flor- ida, when hospitals using yellow DNR wristbands (as was the case in 3 hospitals in our sample) reported several near-misses among patients wearing yellow Lance Armstrong Livestrong bracelets. ${ }^{26-27}$ Given recent estimates that nearly 1 in 5 Americans wears these bracelets to support people living with cancer, ${ }^{28}$ even safety-minded journals and national newspapers have highlighted the issue. ${ }^{29-30}$ Most hospitals that continue to use yellow DNR wristbands now either remove or cover Livestrong bracelets at the time of hospital admission. Furthermore, many other self-help organizations now issue wristbands in a variety of colors as well, creating a potential hazard for any person wearing one in the hospital. Although patients do not mind wearing color-coded wristbands, ${ }^{31}$ they might feel differently if they knew the potential for confusion.

After these anecdotal reports of identification mistakes surfaced, several states, most notably Arizona and Pennsylvania, launched initiatives to address the problem. ${ }^{32-33}$ Arizona, after discovering 8 colors being used in the state, developed plans for a purple DNR color-coded wristband. The choice of purple, and the careful decision to avoid blue, occurred because many hospitals call their resuscitative efforts a "code blue," creating yet another potential source of confusion if a blue wristband is associated with a DNR order. The Pennsylvania Patient Safety Authority also found tremendous color variations in patient wristbands used in a statewide survey. Both states ultimately promoted standardized colors and indications and provided tool kits and implementation manuals. ${ }^{32-33}$

Although statewide initiatives represent a step forward, we believe that a national standard for color-coded wristbands would improve patient safety. Precedents for this call to action exist. For many years, anecdotal information circulated about the errors caused by ambiguous use of abbreviations, such as "qd" instead of daily or " $U$ " instead of units. Individual hospitals often banned or limited the use of such abbreviations, but no standard list of high-risk abbreviations guided practice or required adherence, and cross-hospital variation undoubtedly led to confusion. In 2004 the Joint Commission created a uniform list of high-risk abbreviations as part of their National Patient Safety Goals, which instantly ended the debate about which abbreviations to ban and mandated compliance with the safety practice. ${ }^{34}$ A national group of stakeholders should similarly be convened to develop a list of colors and associated conditions 
TABLE 4

Recommendations from Arizona and Pennsylvania for Color-Coded Wristbands

\begin{tabular}{lll}
\hline Indication & Color (PA) & Color (AZ) \\
\hline DNR & Blue & Purple \\
Allergy & Red & Red \\
Fall risk & Yellow & Yellow \\
Latex allergy & Green & - \\
Restricted extremity & Pink & - \\
Preregistration in emergency room & Yellow & - \\
Admission and identification & Clear & - \\
\hline
\end{tabular}

that should be widely disseminated and enforced by the Joint Commission or a similar body. The statewide efforts by Arizona and Pennsylvania are instructive in this regard. Despite being guided by the goal of standardization, these 2 states chose different colors for DNR identification (interestingly, Pennsylvania chose blue for DNR, perhaps for the same reason that Arizona avoided it-code blue), further supporting the need for national guidelines (Table 4).

Our study represents the first national sample of DNR identification practices. Although it targeted academic health centers and affiliated institutions, we believe that these practice variations likely exist in all health care settings. Our study limitations included reliance on self-reported institutional practices rather than direct review of existing policies and limited information about the surveyed population, making it impossible to compare respondents and nonrespondents. However, we have no reason to believe that these groups differed sufficiently to influence the study's main findings.

In the future, better technology may ultimately replace color-coded wristbands. For instance, the time may come when wireless technologies seamlessly linked to the electronic health record will alert providers to a patient's DNR status when entering the patient's room. However, for today, point-of-care solutions using color-coded wristbands remain a reasonable solution. Creating a nationally enforced standardized methodology, understandable and memorable to providers and free of stigma to patients (eg, a black wristband for DNR or writing "DNR" on a wristband) should be a patient safety priority. Because simplification is another key characteristic of safe systems, it seems prudent to aim for a national system that involves a maximum of 3-4 colors.

\section{CONCLUSIONS}

Patients and families dedicate tremendous energy to making decisions about their advance directives, and discussions of these issues often create considerable angst and sadness. Health care providers are trained to elicit and advocate for such directives so they can act with patients' wishes in mind. Despite the high stakes, all these efforts can be undermined when the system for making providers aware of a patient's DNR status is flawed. Our data confirm the tremendous variability in the systems used to indicate DNR status (and other types of indications), variability that may place patients at risk from catastrophic errors. Following the lead of a few states, we call for a national mandate to standardize the identification of DNR orders and to make the colors of wristbands for a small set of indications uniform in every hospital across the country.

Address for correspondence and reprint requests: Niraj L. Sehgal, MD, MPH, Assistant Professor of Medicine, Division of Hospital Medicine, University of California, San Francisco, 533 Parnassus Avenue, Box 0131, San Francisco, CA 94143; Fax: (415) 514-2094; E-mail: nirajs@medicine.ucsf.edu

Received 14 May 2007; revision received 12 July 2007; accepted 20 August 2007.

\section{REFERENCES}

1. Kelley K. The Patient Self-Determination Act. A matter of life and death. Physician Assist. 1995;19(3):53-56.

2. Perkins HS. Controlling death: the false promise of advance directives. Ann Intern Med. 2007;147:51-57.

3. Teno J, Lynn J, Wenger N, et al. Advance directives for seriously ill hospitalized patients: effectiveness with the patient self-determination act and the SUPPORT intervention. SUPPORT Investigators. Study to Understand Prognoses and Preferences for Outcomes and Risks of Treatment. J Am Geriatr Soc. 1997;45:500-507.

4. Baker DW, Einstadter D, Husak S, Cebul RD. Changes in the use of do-not-resuscitate orders after implementation of the Patient Self-Determination Act. J Gen Intern Med. 2003;18: 343-349.

5. Collins SE. Rethinking of the Patient Self Determination Act: implementation without effectiveness. J Nurs Law. 1999;6: 29-46.

6. Comprehensive Accreditation Manual for Hospitals: The Official Handbook. The Joint Commission Resources. Available at: http://www.jcrinc.com/13519/. Accessed May 1, 2007.

7. Baumrucker SJ. Durable power of attorney versus the advance directive: who wins, who suffers? Am J Hosp Palliat Care. 2007;24(1):68-73.

8. Orbon MJ. The "living will"-an individual's exercise of his rights of privacy and self-determination. Loyola Univ Chicago Law J. 1976;7:714-732.

9. Garraty CM. Durable power of attorney for health care: a better choice. Conn Probate Law J. 1992;7(1):115-141. 
10. Pew Research Center for the People and the Press. More Americans Discussing-and Planning-End-of-Life Treatment. January 2006. Available at: http://people-press.org/ reports/. Accessed May 1, 2007.

11. Kohn LT, Corrigan J, Donaldson M, eds. To Err Is Human: Building a Safer Health System. Washington, DC: National Academy Press; 2000.

12. Institute of Medicine (U.S.). Committee on Quality of Health Care in America. Crossing the Quality Chasm: a New Health System for the 21st Century. Washington, DC: National Academy Press; 2001.

13. Leon MD, Wilson EM. Development of a statewide protocol for the prehospital identification of DNR patients in Connecticut including new DNR regulations. Ann Emerg Med. 1999;34:263-274.

14. Adams JG. Prehospital do-not-resuscitate orders: a survey of state policies in the United States. Prehospital Disaster Med. 1993;8:317-322.

15. Hickman SE, Tolle SW, Brummel-Smith K, Carley MM. Use of physician orders for life-sustaining treatment program in Oregon nursing facilities: beyond resuscitation status. $J \mathrm{Am}$ Geriatr Soc. 2004;52:1424-1429.

16. Goldstein, M. Deciphering the Code. Agency for Healthcare Research and Quality Morbidity and Mortality Rounds on the Web. Available at: http://webmm.ahrq.gov/. Accessed May $1,2007$.

17. Wachter R, Shojania K. Internal Bleeding: The Truth Behind America's Terrifying Epidemic of Medical Mistakes. New York, NY: Rugged Land; 2004.

18. Rodriguez KF. Suing health care providers for saving lives. Liability for providing unwanted life-sustaining treatment. $J$ Leg Med. 1999;20(1):1-66.

19. University Health Consortium. Available at: http://www.uhc.edu/. Accessed May 3, 2007.

20. Survey Console. Available at: http://www.surveyconsole.com/. Accessed May 3, 2007.

21. Ash JS, Sittig DF, Poon EG, Guappone K, Campbell E, Dykstra RH. The extent and importance of unintended consequences related to computerized provider order entry. J Am Med Inform Assoc. 2007; April 25 [Epub ahead of print].

22. Han YY, Carcillo JA, Venkataraman ST, et al. Unexpected increased mortality after implementation of a commercially sold computerized physician order entry system. Pediatrics. 2005;116:1506-1512.

23. Wachter RM. Expected and unanticipated consequences of the quality and information technology revolutions. JAMA. 2006;295:2780-2783

24. Hirschtick RE. A piece of my mind. Copy-and-paste. JAMA. 2006;295:2335-2336.

25. McDonald CJ. Computerization can create safety hazards: a bar-coding near miss. Ann Intern Med. 2006; 144:510516.

26. Robeznieks A. Proliferating bracelets could pose hazards for patients. AMA News. 2005;48:13. Available at: http://www.ama-assn.org/amednews/2005/01/03/prsd0103.htm. Accessed March 31, 2007.

27. Hayes S. Wristbands called patient safety risk. St. Petersburg Times. December 10, 2004;1A. Available at: http://www.sptimes.com/home.shtml. Accessed April 3, 2007.

28. Lance Armstrong Foundation. How the LAF is making an impact. Available at: http://www.livestrong.org/. Accessed May 3, 2007.

29. Did You Know: some hospitals asking patients to remove or cover rubber wristbands. Agency for Healthcare Research and Quality Morbidity and Mortality Rounds on the Web. Available at: http://webmm.ahrq.gov/. Accessed May 1, 2007.

30. Landro L. Hospitals target risks of color wristbands. Wall Street Journal. April 4, 2007: D5.

31. Cleopas A, Kolly V, Bovier PA, Garnerin P, Perneger TV. Acceptability of identification bracelets for hospital inpatients. Qual Saf Health Care. 2004;13:344-348.

32. Color-Coded Wristband Standardization in Arizona: a Toolkit. Arizona Hospital and Healthcare Association: Safe \& Sound. Available at: http://www.azhha.org/public/quality/. Accessed May 1, 2007.

33. Patient Safety: Color Banding, Standardization and Implementation Manual. Pennsylvania Patient Safety Authority. Available at: http://www.psa.state.pa.us/psa/. Accessed May 1, 2007.

34. The Official "Do Not Use" List. The Joint Commission. Available at: http://www.jointcommission.org/PatientSafety/DoNotUseList/. Accessed May 1, 2007. 